\title{
Avaliação da diversidade genética de amostras de Cryptococcus neoformans isoladas em diferentes regiões geográficas
}

Evaluation of genetic diversity of Cryptococcus neoformans samples isolated in different geographical regions

Evaluación de la diversidad genética de muestras de Cryptococcus neoformans aisladas en diferentes regiones geográficas

Dakson Douglas Araújo

ORCID: https://orcid.org/0000-0003-0102-7240

Universidade Federal do Delta do Parnaíba, Brasil E-mail: dacksondouglas@gmail.com

Raí Emanuel da Silva

ORCID: https://orcid.org/0000-0002-4266-0475 Universidade Federal do Piauí, Brasil

E-mail: raiemanuel@hotmail.com

Higinalice da Silva Pereira

ORCID: https://orcid.org/0000-0002-0119-819X

Universidade Federal do Delta do Parnaíba, Brasil

E-mail: alice_higina@hotmail.com

Dacylla Sampaio Costa

ORCID: https://orcid.org/0000-0002-9909-7353

Universidade Federal do Delta do Parnaíba, Brasil E-mail: dacyllasampaio@hotmail.com

Rodrigo Elísio De Sá

ORCID: https://orcid.org/0000-0002-1492-3995

Universidade Federal do Delta do Paranaíba, Brasil

E-mail: rodrigosa238@gmail.com

Antonio Rodrigues da Silva Neto

ORCID: https://orcid.org/0000-0003-0054-510X Universidade Estadual do Piauí, Brasil

E-mail: antonionettors5@gmail.com

Nathanael Dos Santos Alves

ORCID: https://orcid.org/0000-0001-6945-6282

Universidade Federal do Delta do Parnaíba, Brasil E-mail: santosnathanae155@gmail.com

Fernanda Machado Fonseca

ORCID: https://orcid.org/0000-0002-5326-0776

Universidade Federal do Triângulo Mineiro, Brasil E-mail: fmachadofonseca@gmail.com

\begin{abstract}
Resumo
Cryptococcus neoformans é o agente etiológico da criptococose, uma infecção fúngica oportunista e ocorre frequentemente em pacientes imunodeprimidos, com uma doença de base, afetando principalmente o sistema nervoso central e os pulmões. Análises de sequências genômicas de microrganismos por meio de filogenias têm demonstrado um amplo espectro de aplicações na pesquisa científica e na medicina. Na área da saúde, a utilização desta ferramenta auxilia no diagnóstico e consequentemente na elaboração de programas para melhor tratamento e controle das doenças. Ainda, a análise filogenética é importante para caracterizar novas espécies que possam vir a sofrer possíveis recombinações genéticas, que na grande maioria das vezes é responsável pela resistência de patógenos frente ao tratamento. Desta forma, o presente estudo teve como objetivo analisar a variabilidade genética dos genes $18 \mathrm{~S}$ e $28 \mathrm{~S}$ de $C$. neoformans em diferentes regiões geográficas. Foram selecionadas 191 sequências gênicas do gene $18 \mathrm{~S}$ e 132 sequências gênicas do gene $28 \mathrm{~S}$ para realização das análises filogenéticas e Split. Os resultados demonstraram que o gene $28 \mathrm{~S}$ tem uma maior variabilidade genética se comparado ao gene $18 \mathrm{~S}$ que se mostrou mais conservado. Essa variabilidade pode ser resultante de recombinações genéticas e migrações de cepas diferentes de uma região geográfica para outra, como por exemplo, através do turismo de indivíduos portadores do fungo. Além disso, a recombinação genética pode resultar futuramente em uma nova espécie com capacidade de causar doenças no homem.
\end{abstract}

Palavras-chave: Cryptococcus neoformans; Filogenia; Recombinação genética. 


\begin{abstract}
Cryptococcus neoformans is the etiological agent of cryptococcosis, an opportunistic fungal infection and frequently occurs in immunocompromised patients, with an underlying disease, mainly affecting the central nervous system and lungs. Analysis of genomic sequences of microorganisms through phylogenies has demonstrated a wide spectrum of applications in scientific research and medicine. In the health area, the use of this tool contributes to the diagnosis and consequently to the development of programs to improve the treatment and control of diseases. Furthermore, the phylogenetic analysis is important to characterize new species that can development possible genetic recombinations, which in most cases is responsible for the resistance of pathogens to the treatment. Thus, this study aimed to analyze the genetic variability of $18 \mathrm{~S}$ and $28 \mathrm{~S}$ genes of $C$. neoformans in different geographic regions. Were selected 191 sequences of the $18 \mathrm{~S}$ gene and 132 sequences of the $28 \mathrm{~S}$ gene to carry out phylogenetic and split analyses. The results demonstrated that the $28 \mathrm{~S}$ gene has more genetic variability when compared to the $18 \mathrm{~S}$ gene, which has been shown to be more conserved. This variability can be a result from genetic recombination and migration of different strains from one geographic region to another through the tourism of individuals with the fungal. Additionally, in the future, this genetic recombination can result in a new species capable of causing diseases in humans.
\end{abstract}

Keywords: Cryptococcus neoformans; Phylogeny; Recombination genetic.

\begin{abstract}
Resumen
Cryptococcus neoformans es el agente etiológico de la criptococosis, una infección micótica oportunista y ocurre con frecuencia en pacientes inmunodeprimidos, con una enfermedad subyacente, que afecta principalmente al sistema nervioso central y los pulmones. El análisis de secuencias genómicas de microorganismos mediante filogenias ha mostrado un amplio espectro de aplicaciones en la investigación científica y la medicina. En el área de la salud, el uso de esta herramienta ayuda en el diagnóstico y, en consecuencia, en la elaboración de programas para un mejor tratamiento y control de enfermedades. Además, el análisis filogenético es importante para caracterizar nuevas especies que puedan sufrir una posible recombinación genética, que en la mayoría de los casos es responsable de la resistencia de los patógenos al tratamiento. Así, este estudio tuvo como objetivo analizar la variabilidad genética de los genes $18 \mathrm{~S}$ y $28 \mathrm{~S}$ de C. neoformans en diferentes regiones geográficas. Se seleccionaron 191 secuencias de genes del gen $18 \mathrm{~S}$ y 132 secuencias de genes del gen 28S para llevar a cabo los análisis filogenéticos y Split. Los resultados mostraron que el gen $28 \mathrm{~S}$ tiene una mayor variabilidad genética en comparación con el gen 18S, que resultó estar más conservado. Esta variabilidad puede resultar de recombinaciones genéticas y migraciones de diferentes cepas de una región geográfica a otra, por ejemplo, a través del turismo de individuos portadores del hongo. Además, la recombinación genética puede resultar en el futuro en una nueva especie capaz de causar enfermedades en el hombre. Palabras clave: Cryptococcus neoformans; Filogenia; Recombinación genética.
\end{abstract}

\title{
1. Introdução
}

Cryptococcus neoformans é a forma assexuada do basidiomiceto Filobasidiella neoformans, levedura encapsulada de grande importância na micologia médica que tem a capacidade de infectar e causar doença. É o agente causador da criptococose, doença sistêmica subaguda ou crônica, cosmopolita, descrita inicialmente no fim do século XIX, cuja ocorrência antes da epidemia da AIDS (Acquired Immunodeficiency Syndrome) era esporádica e geralmente associada a pacientes com baixa imunidade celular (Reolon; Perez; Mezzari, 2004; Araújo Júnior et al., 2015; Srikanta; Santiago-Tirado; Doering, 2015).

A célula leveduriforme de $C$. neoformans possui aproximadamente dois a oito micrômetros de diâmetro e sua cápsula é constituída por mucopolissacarídeos, sendo $90 \%$ glucoronoxilomananos (GXM): Ácido glucurônico, xilose e manose. $C$. neoformans foi classificado em quatro sorotipos (A-D) de acordo com as propriedades antigênicas de sua cápsula de polissacarídeo e a espécie Cryptococcus gatti, originalmente sorotipos B e C, foi posteriormente classificado como uma nova espécie. Assim, C. neoformans foi dividido em duas variedades sendo C. neoformans var. neoformans (sorotipo D) e C. neoformans var. grubii (sorotipo A) (Costa et al., 2010).

A criptococose é uma infecção subaguda ou crônica que pode envolver os pulmões, a pele e outros sítios anatômicos, mas tem predileção pelo cérebro e meninges (Desnos et al., 2010). A história natural da doença fúngica em geral está diretamente relacionada com a suscetibilidade do hospedeiro e geralmente determina a gravidade da infecção. A via de entrada das células fúngicas no hospedeiro se dá pela inalação de propágulos do microrganismo no ambiente, que se depositam no alvéolo pulmonar. A disseminação pode ocorrer para outros sítios, provavelmente por via hematogênica, com especial tropismo para o cérebro e meninges (Costa et al., 2010; Araújo et al., 2015). 
Fatores como as defesas do hospedeiro, a virulência do microrganismo e a quantidade do inóculo estão diretamente relacionados a patogênese da infecção. De modo geral, o primeiro aspecto microbiológico importante para o estabelecimento da infecção é a aderência e colonização do tecido do hospedeiro pelo fungo. C. neoformans é um patógeno intracelular facultativo, portanto, capaz de sobreviver em macrófagos e permanecer na vesícula ácida fagossômica, mantendo sua capacidade de multiplicação (Costa et al., 2010; Reolon; Perez; Mezzari, 2004; Araújo et al., 2015; Silva et al., 2021).

C. neoformans infecta principalmente pacientes com AIDS e imunocomprometidos, sendo que nesses casos, a maioria dos pacientes desenvolve a forma disseminada da doença, enquanto que indivíduos imunocompetentes também podem ser infectados e desenvolvem, geralmente, a forma pulmonar causada pela espécie $C$. gattii. A principal e mais grave manifestação clínica é a meningoencefalite, que ocorre principalmente nos pacientes com AIDS. Os sintomas são variados entre os quais o indivíduo pode apresentar cefaleia, febre, letargia, perda de memória, mal estar, papiledema. As complicações podem ser comuns e incluem o aumento da pressão intracraniana, perda visual ou auditiva e menos frequente, a diminuição cognitiva e ataxia em função da hidrocefalia. Na ausência de tratamento terapêutico eficaz e de rápido início, o paciente evolui a óbito (Araújo et al., 2015; Desnos et al., 2010; Sloan; Parris, 2014).

Nos últimos anos, observa-se um aumento na frequência de infecções fúngicas graves, especialmente por fungos oportunistas, como resultados do avanço na terapia médica, transplantes de órgãos, crescimento da população geriátrica, e condições imunossupressoras, como infecções pelo HIV. Estudos que buscam caracterizar os isolados clínicos destas espécies são importantes sob o ponto de vista epidemiológico e microbiológico, pois, permitem entender a biologia do agente, e relacionar as características fenotípicas e moleculares com os fatores envolvidos na virulência do agente, como a correlação entre genótipo e o desfecho da infecção (Galiza et al., 2014; Aguiar et al., 2017; Silva et al., 2021). O diagnóstico da criptococose pode ser feito a partir de diferentes tipos de amostras de acordo com a apresentação clínica no paciente, como LCR (líquido cefalorraquidiano ou líquor), urina, fragmentos de tecido, aspirados de lesões cutâneas, escarro e amostras do trato respiratório, entre outras. São realizados exame direto, cultura, histologia e sorologia (Costa et al., 2010).

O tratamento da criptococose tem sido alvo de inúmeros estudos e três classes de drogas antifúngicas têm sido consideradas para este fim: os poliênicos (anfotericina B), os azóis (cetoconazol, itraconazol, fluconazol e voriconazol) e o derivado piramidínico (5-flucitosina) (Sloan; Parris, 2014). No Brasil, entretanto, a 5-flucitosina não é dispoibilizada (Severo; Gazzoni; Severo, 2009). A anfotericina-B tem sido considerada para o tratamento das infecções fúngicas mais graves associada ou não ao fluconazol. Entretanto, cabe ressaltar que os vários efeitos colaterais da anfotericina B limitam a sua utilização, sendo o fluconazol, portanto, o que oferece uma terapia mais segura e com maior eficácia (Moreira et al., 2006; Costa et al., 2010). Para o tratamento das formas pulmonares (progressiva e disseminada) tanto em pacientes imunocompetentes como em imunossuprimidos, existe indicação de tratamento com antifúngico específico. Para formas exclusivamente pulmonares, podese utilizar intraconazol por seis meses ou mais, de acordo com a evolução da doença (Reolon; Perez; Mezzari, 2004; Araújo Júnior et al., 2015).

Os métodos de identificação moleculares são os mais recentes e são úteis em estudos epidemiológicos, para a identificação da variedade, do sorotipo e variações individuais de cepas. A técnica de PCR (Reação em Cadeia da Polimerase) demonstra níveis de sensibilidade e especificidade superiores à cultura e ao exame direto pela tinta da China. A PCR, sendo sensível, específica e reprodutível, representa uma ferramenta promissora para a análise de amostras de líquor em pacientes com suspeita clínica de meningoencefalite, podendo ainda ser utilizado como teste de identificação de Cryptococcus spp. (Silva, 2012; Nascimento et al., 2020; Arechavala et al., 2018).

As análises de sequências genômicas por meio de filogenias moleculares têm demonstrado um amplo espectro de aplicações. Dentre as principais aplicações das análises filogenéticas inclui-se a investigação por polimorfismos envolvidos na seleção natural, a detecção de pontos de recombinação, a descoberta de mutações que apresentam íntima relação a distúrbios 
ou doenças, além da identificação de novos patógenos. Todas estas aplicações são desenvolvidas por meio da utilização de sequências de nucleotídeos e/ou aminoácidos, que permitem traçar todo perfil molecular envolvido (Caldart, Mata, Canal \& Ravazzolo, 2016).

$\mathrm{Na}$ área da saúde a utilização destas ferramentas moleculares auxilia no diagnóstico e consequentemente, na elaboração de programas de melhor tratamento e controle das doenças. Além disso, é importante para caracterizar novas espécies que possam sofrer possíveis recombinações genéticas e que na maioria das vezes é responsável pela resistência de patógenos frente a tratamentos. A filogenia para caracterização molecular estabelece o conhecimento das linhagens circulantes em determinados locais e fornece subsídios para elaborar estratégias de imunização condizentes com as necessidades reais. Neste sentido, o presente trabalho teve como objetivo realizar uma análise filogenética dos genes $18 \mathrm{~S}$ e $28 \mathrm{~S}$ de isolados de $C$. neoformans proveniente de diversas regiões geográficas.

\section{Metodologia}

Foram selecionadas 191 sequências parciais do gene ribossomal 18S e 132 sequências do gene ribossomal 28S de Cryptococcus neoformans var. neoformans e var. grubbii provenientes de várias regiões geográficas do mundo. As sequências obtidas estão disponibilizadas no banco de dados do PubMed (National Library of Medicine) através do site https://www.ncbi.nlm.nih.gov/pubmed/.

As amostras de sequências selecionadas foram provenientes de artigos científicos os quais a busca foi realizada com as palavras-chave "Cryptococcus neoformans and 18S" e "Cryptococcus neoformans and 28S". As sequências parciais foram então organizadas em banco de dados no Excel contendo número de acesso, fonte da amostra, região geográfica, sequências gênicas parciais e autores dos artigos utilizados como referência.

Inicialmente, foi realizado o alinhamento múltiplo das amostras selecionadas para cada gene pelo software Clustal W. A confirmação da espécie foi realizada pela submissão das mesmas no programa BLAST ${ }^{\circledR}$ (Basic Local Alignment Search Tool - NIH). A análise filogenética dos genes $18 \mathrm{~S}$ e $28 \mathrm{~S}$ foi realizada no software MEGA $5.0^{\circledR}$ com o método de Agrupamento de Vizinhos (Neighbour Joining, NJ) (Tamura et al., 2011; Saitou \& Nei, 1987), sob o modelo Maximum Composite Likelihood para correção das distâncias nucleotídicas. A confiabilidade da árvore filogenética foi estimada pelo método de Bootstrap com 1000 réplicas (Felsenstein, 1985). O modelo de Neighbour Joining é considerado simples e rápido, principalmente ao realizar análise de um grande volume de dados. Tal modelo no geral, é utilizado em trabalhos que utilizam análise de sequências de DNA, tendo em vista que sua finalidade é identificar sequências por meio da similaridade existente entre elas e não de fornecer uma hipótese filogenética definitiva.

Posteriormente, foi avaliada a recombinação genética das sequências parciais de cada gene no programa Split Tree ${ }^{\circledR}$ versão 4.14 .

\section{Resultados}

Dentre as 191 sequências parciais do gene $18 \mathrm{~S}$ de C. neoformans, 106 (55,4\%) eram provenientes da China, 16 (8,4\%) eram provenientes do Brasil, 15 (7,8\%) eram proveniente da Itália, 14 (7,3\%) da Austrália, oito (4,2\%) eram provenientes do Japão, seis $(3,1 \%)$ do México, seis $(3,1 \%)$ da Índia, cinco $(2,6 \%)$ sequências eram provenientes de isolados da França, quatro $(2,1 \%)$ dos Estados Unidos, duas $(1,0 \%)$ da Grécia, duas $(1,0 \%)$ do Irã, duas $(1,0 \%)$ do Kuwait e uma $(0,5 \%)$ amostra tinha procedência da Argentina, do Chile, do Egito, do Reino Unido e Holanda.

Em relação às sequências parciais do gene 28S, sendo 64 (44.5\%) das 132 eram provenientes dos Estados Unidos, 35 (26,5\%) eram provenientes de Botswana na África, 14 (10,6\%) do Brasil, seis $(4,5)$ do Peru, cinco $(3,7 \%)$ da Holanda, quatro $(3,0 \%)$ da Tailândia, uma $(0,7 \%)$ da Austrália, da Índia, da Itália e República do Congo. 
Quando avaliamos a fonte de isolamento de todas as amostras incluídas no presente estudo, 167 (51,7\%) eram de amostras clínicas de líquido cefalorraquidiano, seguido de 34 (10,5\%) amostras de isolados ambientais de excretas secas de pombo, $12(3,7 \%)$ eram de isolados de sangue periférico, 10 (3,1\%) eram isolados a partir de amostra clínica de pacientes com doença pulmonar e em 100 (31\%) amostras não foi possível identificas a fonte.

De acordo com a análise filogenética referente ao gene 18S (Figura 1), observamos a formação de dois grandes grupos. O primeiro grupo, apresentou valor de bootstrap de 47 e dentro dele observamos vários subgrupos. Considerando ainda este primeiro grupo, foi possível observar uma divisão em um outro subgrupo separado e que demonstrou valores de bootstrap interessantes, de 99 para as três amostras provenientes da Índia KJ17593.1.060IN, KJ175192.1.061IN e KJ175191.1.062IN.

Ainda, observamos a formação de um segundo grupo maior, que também se subdividiu em vários subgrupos, entretanto, com baixos valores de bootstrap. Apesar de observarmos um valor de bootstrap de 98 em um clado da árvore, os demais valores de bootstrap dos subgrupos são baixos e não representam variações genéticas significativas (Figura 1). 
Figura 1. Análise filogenética do gene $18 \mathrm{~S}$ de isolados de Cryptococcus neoformans geradas através da análise de sequências de nucleotídeo no software MEGA 5.0® pelo método Neighbour-joining e distância $p$ (bootstrap 1000 replicatas) demonstrado próximo aos braços. A distância evolucionária calculada pelo método (Maximum Composite Likelihood) utilizada para inferir a árvore filogenética.

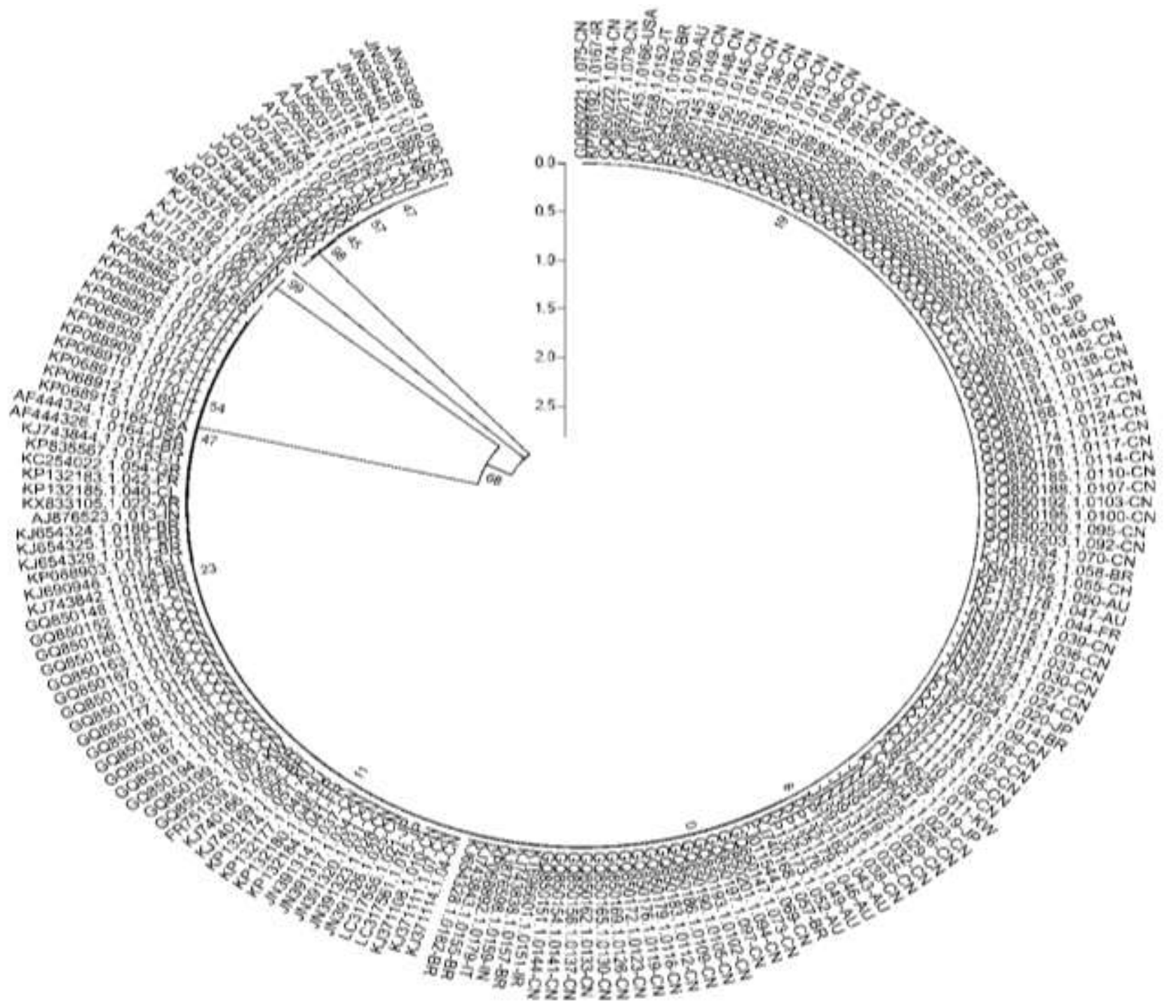

Fonte: Dados da pesquisa (2021).

A árvore filogenética do gene $28 \mathrm{~S}$ demonstrou a formação de três grandes grupos (Figura 2). O primeiro grupo foi formado exclusivamente por amostras provenientes dos Estados Unidos apresentando valor de bootstrap de 99 e dentro dele, foi possível observar a formação de subgrupos também com valores significativos de bootstrap.

O segundo grupo foi formado por amostras de vários países que apresentaram altos valores de bootstrap entre si, de 100. Mesmo com a formação de subgrupos, observamos ainda bootstrap elevados de 84,86 e 88 , demonstrando a diversidade deste grupo.

Finalmente, no terceiro grupo formado a partir da análise do gene 28S, observamos que as amostras de Botwsana se agruparam em clados separados e ainda assim, apresentaram altos valores de bootstrap de 95,97 e 100. 
Figura 2. Análise filogenética do gene $28 \mathrm{~S}$ de isolados de Cryptococcus neoformans geradas através da análise de sequências de nucleotídeo no software MEGA 5.0® pelo método Neighbour-joining e distância $p$ (bootstrap 1000 replicatas) demonstrado próximo aos braços. A distância evolucionária calculada pelo método (Maximum Composite Likelihood) utilizada para inferir a árvore filogenética.

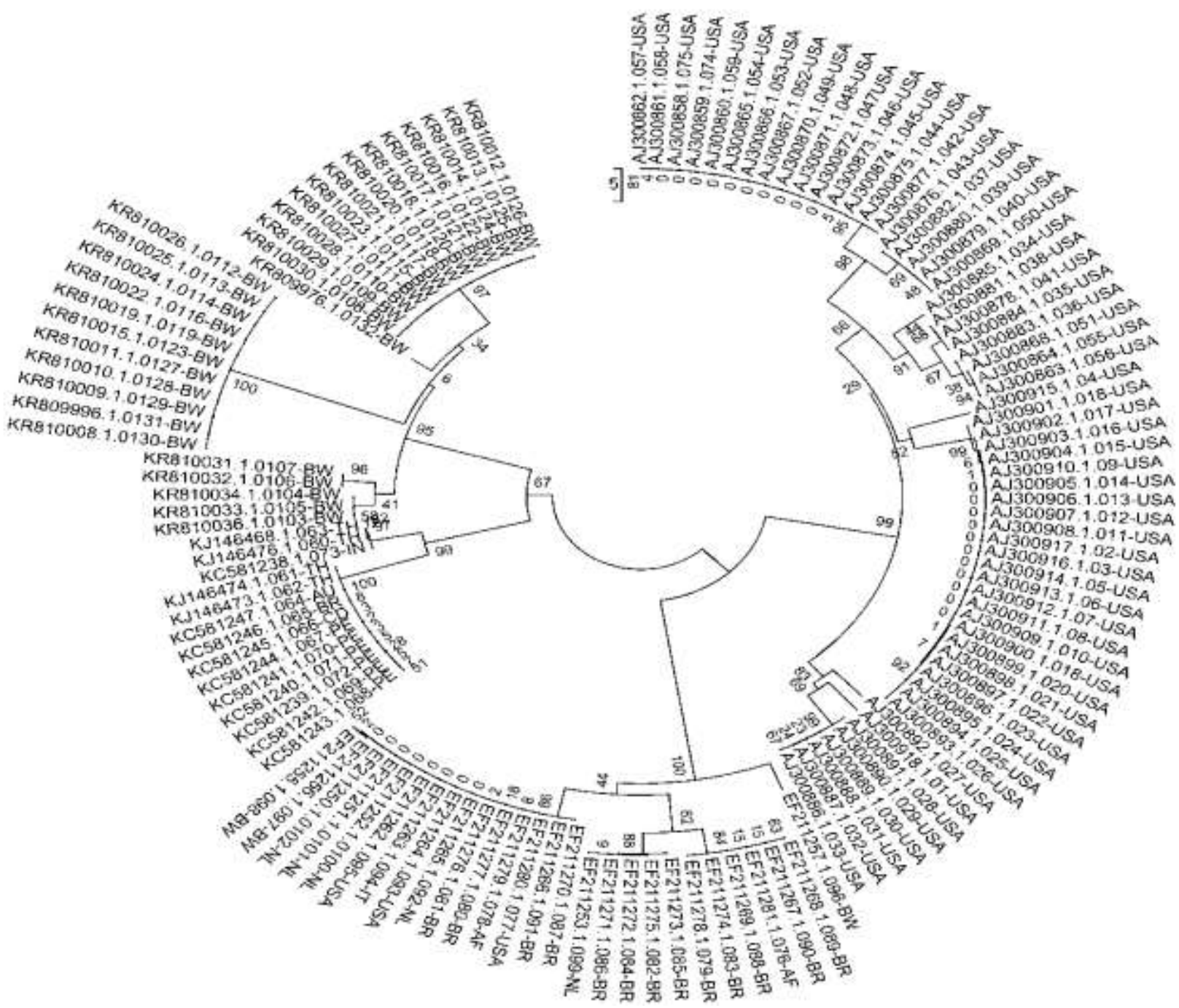

Fonte: Dados da pesquisa (2021)

De forma geral, as sequências gênicas do gene $28 \mathrm{~S}$ demonstraram uma maior variabilidade genética do que aquelas avaliadas para o gene 18S. Tais eventos de recombinação ficam evidentes quando analisamos as sequências parciais pelo método Split para os genes 18S (Figura 3) e 28S (Figura 4), respectivamente. 
Research, Society and Development, v. 10, n. 9, e51410918333, 2021

(CC BY 4.0) | ISSN 2525-3409 | DOI: http://dx.doi.org/10.33448/rsd-v10i9.18333

Figura 3. Análise da recombinação genética das sequências do gene 18S de Cryptococcus neoformans (Split Tree4).

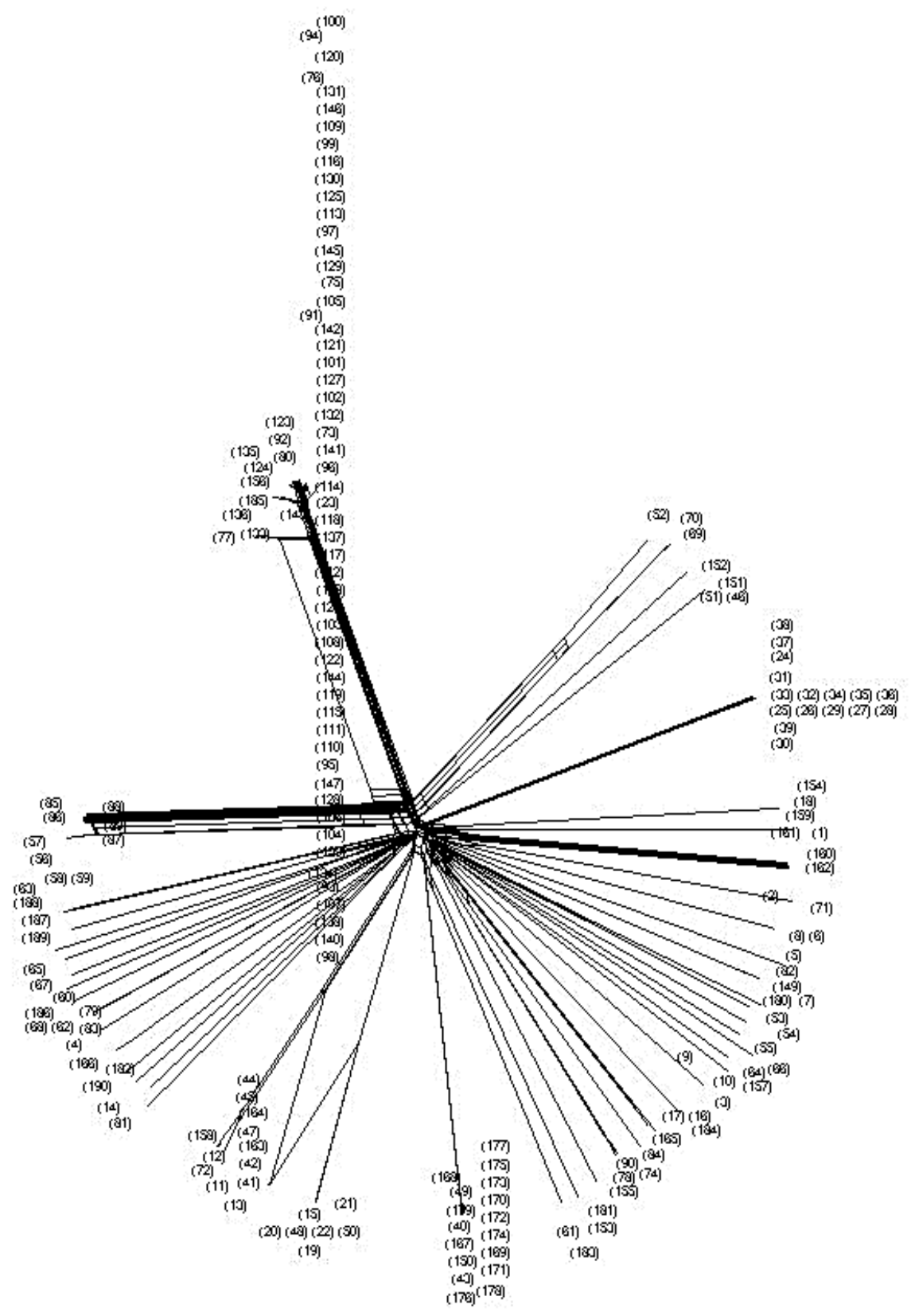

Fonte: Dados da pesquisa (2021) 
Figura 4. Análise da recombinação genética das sequências do gene $28 \mathrm{~S}$ de Cryptococcus neoformans feito pelo programa Split Tree4.

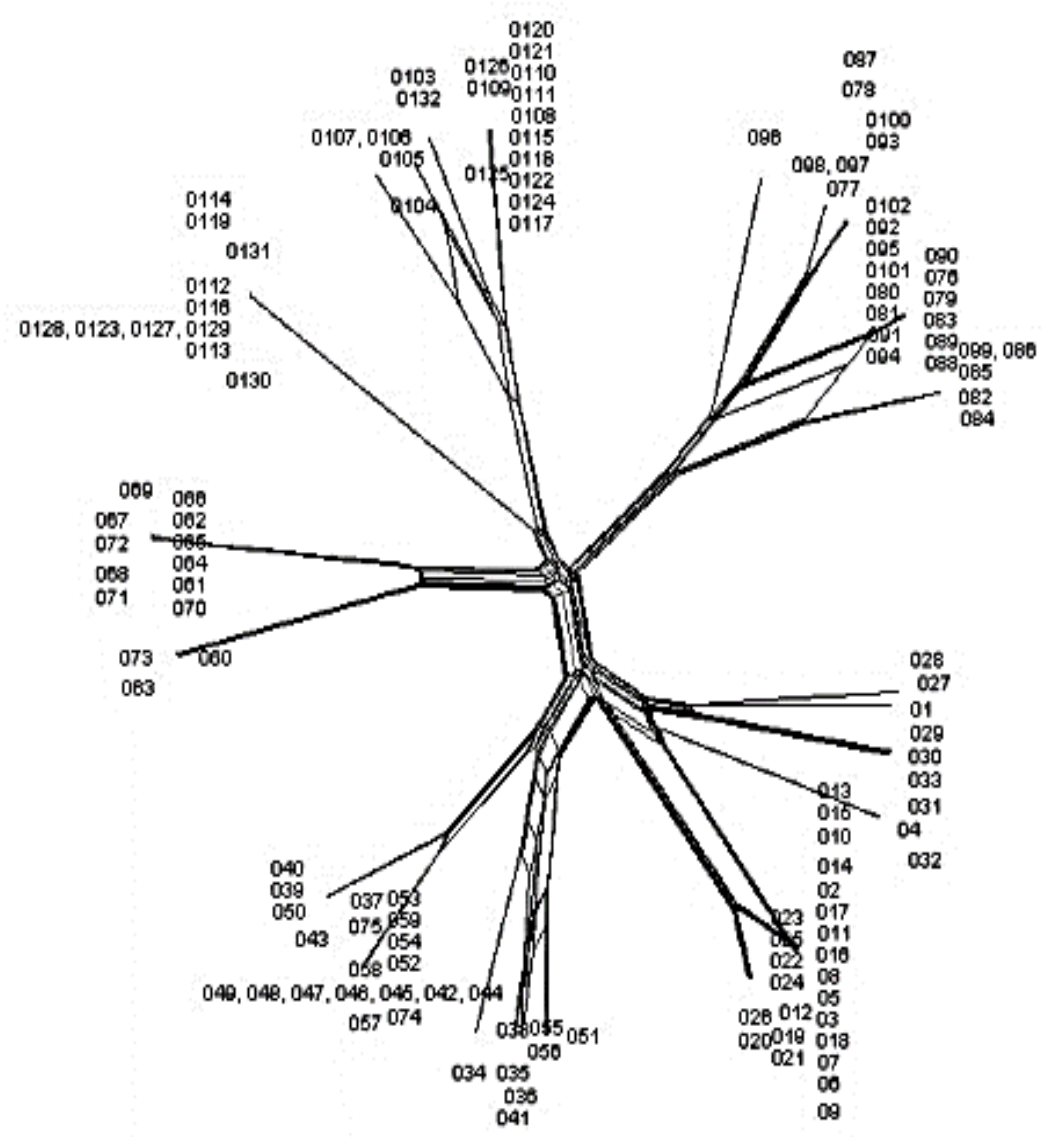

Fonte: Dados da pesquisa (2021)

\section{Discussão}

A criptococose é uma doença fúngica que afeta uma enorme quantidade de pessoas em todo o mundo a cada ano. No Brasil, os dados sobre essa doença baseiam-se na análise de casos diagnosticados em centros regionais de saúde ou por meio de casos indiretos obtidos pelo Departamento de doenças sexualmente transmissíveis/HIV-AIDS do Ministério da Saúde do Brasil. As infecções fúngicas estão emergindo rapidamente, no entanto, ainda tem muito o que se pesquisar sobre a epidemiologia global, para que sejam desenvolvidas terapias mais eficazes para essa doença (Pinheiro et al., 2019; Nascimento et al., 2020).

Leveduras do complexo $C$. neoformans são a segunda maior causa de infecção fúngica oportunista, tanto em humanos como em animais. Apesar da incidência da criptococose ser relativamente baixa em países desenvolvidos, nos países em desenvolvimento o número de casos vem crescendo de forma alarmante, de forma que cepas altamente virulentas vem se espalhando pelo mundo (Santiago-Tirado; Doering, 2015; Pizzani; Santos, 2017; Srikanta).

As informações relacionadas à frequência de isolamento do fungo em diferentes partes do mundo contribuem para avaliar epidemiologicamente o gênero Cryptococcus, além de favorecer o entendimento dos fatores que possam estar relacionados à sua sobrevivência e desenvolvimento nos diferentes ambientes (Hagen et a., 2015). Neste sentido, a análise 
filogenética representa uma importante técnica que pode ser utilizada para identificar e analisar a evolução entre os organismos, através de sequências de genes ou proteínas (Ajawatanawong, 2016). Além disso, é importante destacar que determinando a caracterização molecular é possível estabelecer o conhecimento das linhagens circulantes em uma região e, desta forma, estratégias que atendam às necessidades reais possam ser pensadas (Caldart, Mata, Canal \& Ravazzolo, 2016).

Os métodos de análise empregados foram desenvolvidos para traçar os caminhos evolutivos percorridos ao longo do tempo, mas atualmente as análises filogenéticas são utilizadas em diversas áreas, tais como epidemiologia molecular, detecção de funções genéticas, biologia sistemática e biodiversidade, e identificação de microrganismos em estudos de microbioma (Ajawatanawong, 2016).

Segundo Araújo Júnior et al. (2015) a identificação de espécies de Cryptococcus, em todo o mundo ainda era pouco realizada por análise molecular. Entretanto, tais estudos filogenéticos têm sido cada vez mais realizados na atualidade. As informações aprofundadas, obtidas a partir da filogenia, contribuem para o entendimento de quais genótipos podem estar envolvidos em determinadas regiões, bem como entender melhor o potencial de virulência, susceptibilidade frente a antifúngicos e manifestações clínicas das doenças que estas cepas podem causar. Portanto, é cada vez mais necessário identificar as espécies de Cryptococcus em nível molecular, para que seja possível traçar um perfil epidemiológico adequado para essa levedura e contribuir para a vigilância ambiental

Muitos estudos que investigam a performance populacional, estabelecem relações entre a variabilidade genética do agente etiológico/patógeno e a variabilidade genética do hospedeiro (Caldart, Mata, Canal \& Ravazzolo, 2016). Entretanto, a espécie C. neoformans não teve, ao longo de sua evolução, uma relação frequente com células do hospedeiro, e desta forma acredita-se que provavelmente este fungo tenha desenvolvido seus fenótipos relacionados à virulência, em meio à sobrevivência no meio ambiente ou na interação com hospedeiros não humanos. A diversidade de ambientes que este fungo vem experimentando evolutivamente tem selecionado atributos que o permitem sobreviver e proliferar em diferentes ambientes, mesmo os mais inóspitos (O’Meara et al., 2014; Araújo Júnior et al., 2015).

A distribuição mundial dos sorotipos desta espécie demonstra que os isolados ambientais e clínicos do sorotipo A é cosmopolita, enquanto que os sorotipos B e C estão principalmente limitados a regiões tropicais e subtropicais. Entretanto, o nicho ecológico de $C$. gattii tem se expandido devido às descobertas dessa levedura em zonas de clima temperado. Já a ocorrência de Cryptococcus do sorotipo D é pouco relatada, exceto nos Estados Unidos, em alguns países da Europa e nas regiões Sul e Sudeste do Brasil, onde há pouco tempo foi isolado (Paim et al., 2001; Trilles et al., 2008; Araújo Júnior et al., 2015;).

A análise de sequências gênicas ainda permite relacionar os microrganismos com base na similaridade dos seus genes e não somente na sua morfologia (Moreira et al., 2006). Os resultados do presente estudo demonstraram que o gene 18S é mais conservado do que o gene 28S para as amostras avaliadas de Cryptococcus neoformans. Desta forma, a maior variabilidade genética observadas no gene $28 \mathrm{~S}$ pode ser explicada por recombinações genéticas e migrações de cepas diferentes de uma região geográfica para outra através do turismo de indivíduos portadores do fungo, por exemplo. Além disso, a recombinação genética está relacionada de forma que podem afetar a distribuição, patogenicidade, ecologia e até mesmo na resistência do $C$. neoformans frente aos antifúngicos. Entretanto, o resultado do presente estudo não nos permite avaliar se outros genes de $C$. neoformans também são conservados ou se sofreram maiores números de recombinações genéticas.

Um estudo realizado por Ferreira-Paim et al. (2014), teve como objetivo avaliar aspectos moleculares de isolados de Cryptococcus laurentii no Brasil, Botsuana, Canadá e Estados Unidos. Foram analisados 100 isolados de C. laurentii identificados fenotipicamente e foram avaliados por sequenciamento do gene ribossômico de subunidade pequena de $18 \mathrm{~S}$ (18S-SSU), região D1 / D2 do gene de RNA ribossomal de subunidade grande 28S nuclear (28S-LSU) e espaçador transcrito (ITS) da região ribossômica. Os resultados demonstraram a identificação de 75 cepas de C. laurentii que compartilhavam 99- 
100\% de identidade com C. laurentii CBS 139. Um total de nove isolados compartilhou 99\% de identidade com ambos Bullera sp. VY-68 e C. laurentii RY1. Um isolado compartilhou 99\% de identidade com Cryptococcus rajasthanensis CBS 10406, e oito isolados compartilharam 100\% de identidade com Cryptococcus sp. APSS 862 de acordo com as regiões 28S-LSU e ITS e designado como Cryptococcus aspenensis sp. nov. (CBS 13867). Enquanto 16 isolados compartilhavam 99\% de identidade com Cryptococcus flavescens CBS 942 de acordo com a sequência 18S-SSU, apenas seis foram confirmados usando as sequências da região 28S-LSU e ITS. Os 10 restantes compartilhavam 99\% de identidade com o Cryptococcus terrestris CBS 10810, descrito recentemente no Brasil. De forma geral, o sequenciamento permitiu a caracterização de $75 \%$ dos isolados ambientais de $C$. laurentii de diferentes áreas geográficas e a identificação de sete haplotótipos dessa espécie.

A análise da variabilidade genética de isolados clínicos e ambientais do complexo C. neoformans / C. gattii VNI por meio do método de MLST, que consiste em um tipo de análise filogenética com base na caracterização molecular de uma sequência multilocus, foi realizado no Brasil. Os dados obtidos demostraram uma estrutura populacional clonal de $C$. neoformans var. grubii VNI, com uma baixa variabilidade, quando comparada com populações de diferentes continentes. Segundo os autores, essa menor variabilidade resulta, provavelmente, de vários eventos recentes de dispersão da África para as Américas (Ferreira-Paim et al., 2017).

Considerando que a filogenia da espécie C. neoformans apresenta uma expansão populacional exponencial, consistente com o aumento do número de hospedeiros suscetíveis, Ashton et al. (2019) realizaram uma análise do genoma de 699 isolados de Cryptococcus para descrever a estrutura da população de C. neoformans. Os autores verificaram que houve uma recente expansão para esta espécie, e que provavelmente isso possa ter ocorrido devido ao aumento do número de pessoas suscetíveis à infecção. Além disso, o avanço desta variabilidade foi ocasionado pela presença de três subclados de $C$. neoformans (VNIa-4, VNIa-5 e VNIa-93), segundo os dados analisados pelos autores. Esses três grupos estavam concentrados principalmente em isolados oriundos de regiões como Vietnã, Tailândia, Uganda e Malaui.

Ao tempo que se observa a realização de estudos semelhantes, com objetivos em comuns, em compreender diversidade genética da espécie $C$. neoformans, os resultados do presente estudo contribuem para o entendimento variabilidade genética apresentada por esse microrganismo, ao longo do tempo. Esse acompanhamento, ao passo que permite uma análise abrangente da evolução molecular, também permite determinar as variações genéticas responsáveis por tal evento.

Diante do exposto, é possível observar a importância de se avaliar padrões de mutações e variações genéticas referentes a microrganismos, em especial para a espécie $C$ neoformans, uma vez que esta representa um importante agente infeccioso responsável por quadros infecciosos de alta complexidade. Ressalta-se que mais estudos devem ser realizados, de modo que se possa acompanhar a evolução destas linhagens e partir disso, estabelecer ações que visem o controle de tal expansão.

\section{Conclusão}

De acordo com análise filogenética dos genes $18 \mathrm{~S}$ e $28 \mathrm{~S}$ de $C$. neoformans, foi demonstrado que as amostras do gene $28 \mathrm{~S}$ sofrem uma maior variabilidade genética se comparado ao gene $18 \mathrm{~S}$ que se mostrou mais conservado. Futuramente, acreditamos que as mutações seguidas na sequência gênica de alguns isolados do presente estudo podem vir a resultar em uma nova espécie. De forma geral, os isolados do Cryptococcus neoformans sofrem alguns eventos de recombinação gênica, quando avaliados nas diferentes regiões geográficas. Estudos desta natureza são de grande relevância do ponto de vista evolutivo, pois, permitem observar a capacidade dos microrganismos em adquirir novas características que podem resultar em mutações no seu material genético.

Dessa forma, o presente estudo abre perspectivas para o desenvolvimento de novas investigações quanto a abordagem de pesquisas filogenéticas com finalidade de oferecer informações acerca de mutações. Pois, as recombinações genéticas e 
mutações estão diretamente associados com processos evolutivos dos microorganismos, podendo assim resultar em novos fenótipos. Com isso, a constante realização de novas análises permite realizar o acompanhamento dessa evolução, contribuindo desta maneira na tomada de decições no enfretamento da resistência fúngica.

\section{Referências}

Aguiar, P. A. D. F. D., Pedroso, R. D. S., Borges, A. S., Moreira, T. D. A., Araújo, L. B. D., \& Röder, D. V. D. D. B. (2017). The epidemiology of cryptococcosis and the characterization of Cryptococcus neoformans isolated in a Brazilian University Hospital. Revista do Instituto de Medicina Tropical de São Paulo, 59.

Ajawatanawong, P. (2016). Molecular phylogenetics: Concepts for a newcomer. Network Biology, 185-196.

Araújo, E. C., Táparo, C. V., Uchida, C. Y., \& Marinho, M. (2015). Cryptococcus: isolamento ambiental e caracterização bioquímica. Arquivo Brasileiro de Medicina Veterinária e Zootecnia, 67, 1003-1008.

Arechavala, A., Negroni, R., Messina, F., Romero, M., Marín, E., Depardo, R., \& Santiso, G. (2018). Criptococose em Hospital de Doenças Infecciosas de Buenos Aires, Argentina. Revisão de 2.041 casos: Diagnóstico, aspectos clínicos e terapêutica. Revista iberoamericana de micologia , 35 (1), 1-10.

Ashton, P. M., Thanh, L. T., Trieu, P. H., Van Anh, D., Trinh, N. M., Beardsley, J., \& Day, J. N. (2019). Three phylogenetic groups have driven the recent population expansion of Cryptococcus neoformans. Nature communications, 10(1), 1-10.

Caldart, E. T., Mata, H., Canal, C. W., \& Ravazzolo, A. P. (2016). Análise filogenética: conceitos básicos e suas utilizações como ferramenta para virologia e epidemiologia molecular. Acta Scientiae Veterinariae, 44, 1-20.

Costa, A. K., Sidrim, J. J., Cordeiro, R. A., Brilhante, R. S., Monteiro, A. J., \& Rocha, M. F. (2010). Urban pigeons (Columba livia) as a potential source of pathogenic yeasts: a focus on antifungal susceptibility of Cryptococcus strains in Northeast Brazil. Mycopathologia, 169(3), $207-213$.

Desnos-Ollivier, M., Patel, S., Spaulding, AR, Charlier, C., Garcia-Hermoso, D., Nielsen, K., \& Dromer, F. (2010). Infecções mistas e evolução in vivo no fungo patógeno humano Cryptococcus neoformans. MBio, 1 (1), e00091-10.

Faganello, J. (2008). Estudo da variabilidade e diferenças morfológicas entre as espécies Cryptococcus neoformans e Cryptococcus gatii por análise de diferença representacional e microscopia eletrônica de varredura (Tese de Doutorado). Universidade Federal do Rio Grande do Sul, Porto Alegre, Rio Grande do Sul, Brasil.

Felsenstein, J. (1985). Confidence limits on phylogenies: an approach using the bootstrap. evolution, 39(4), 783-791.

Ferreira-Paim, K., Ferreira, T. B., Andrade-Silva, L., Mora, D. J., Springer, D. J., Heitman, J., \& Silva-Vergara, M. L. (2014). Phylogenetic analysis of phenotypically characterized Cryptococcus laurentii isolates reveals high frequency of cryptic species. PLoS One, 9(9), e108633.

Ferreira-Paim, K., Andrade-Silva, L., Fonseca, F. M., Ferreira, T. B., Mora, D. J., Andrade-Silva, J., \& Silva-Vergara, M. L. (2017). MLST-based population genetic analysis in a global context reveals clonality amongst Cryptococcus neoformans var. grubii VNI isolates from HIV patients in Southeastern Brazil. PLoS neglected tropical diseases, 11(1), e0005223

Galiza, G. J., Silva, T. M., Caprioli, R. A., Tochetto, C., Rosa, F. B., Fighera, R. A., \& Kommers, G. D. (2014). Determinação das características histomorfológicas e histoquímicas no diagnóstico da criptococose em animais de companhia. Pesquisa Veterinária Brasileira , 34 (3), $261-269$.

Hagen, F., Khayhan, K., Theelen, B., Kolecka, A., Polacheck, I., Sionov, E., \& Boekhout, T. (2015). Recognition of seven species in the Cryptococcus gattii/Cryptococcus neoformans species complex. Fungal Genetics and Biology, 78, 16-48.

Meyer, W., Aanensen, D. M., Boekhout, T., Cogliati, M., Diaz, M. R., Esposto, M. C., \& Kwon-Chung, J. (2009). Consensus multi-locus sequence typing scheme for Cryptococcus neoformans and Cryptococcus gattii. Medical mycology, 47(6), 561-570.

Moreira, T. D. A., Ferreira, M. S., Ribas, R. M., \& Borges, A. S. (2006). Criptococose: estudo clínico-epidemiológico, laboratorial e das variedades do fungo em 96 pacientes. Revista da Sociedade Brasileira de Medicina Tropical, 39, 255-258.

Nascimento, M. A., Santos, E. C. M., de Carvalho, V. M., Borges, M. S., Ederli, J. P. B., de Albuquerque, C. A. N., \& Moris, D. V. (2020). Perfil de pacientes com criptococose em hospital regional do interior de São Paulo. Research, Society and Development, 9(9), e598997642-e598997642.

O'Meara, T. R., Xu, W., Selvig, K. M., O'Meara, M. J., Mitchell, A. P., \& Alspaugh, J. A. (2014). The Cryptococcus neoformans Rim101 transcription factor directly regulates genes required for adaptation to the host. Molecular and Cellular Biology, 34(4), 673-684.

Pinheiro, M. C., Dos Reis, D. S. T., de Brito, M. T. F. M., \& Quaresma, J. A. S. (2019). Criptococose na Amazônia: uma visão geral atual e perspectivas futuras. Acta tropica , 197,105023

Pizani, A. T., \& dos Santos, M. O. (2017). Criptococose em pacientes HIV positivos: revisão sistemática da literatura. Revista Saúde UniToledo, 1(1).

Reolon, A., Perez, L. R. R., \& Mezzari, A. (2004). Prevalência de Cryptococcus neoformans nos pombos urbanos da cidade de Porto Alegre, Rio Grande do Sul. Jornal Brasileiro de Patologia e Medicina Laboratorial, 40, 293-298.

Rocha, J. É. L., Sousa, R. D. S., \& Fonseca, F. M. (2016). Diversidade Genética De Isolados De Sporothrix schenckii Em Países Do Continente Americano. Revista Uningá Review, 27(3).

Saitou, N., \& Nei, M. (1987). The neighbor-joining method: a new method for reconstructing phylogenetic trees. Molecular biology and evolution, 4(4), 406- 
Research, Society and Development, v. 10, n. 9, e51410918333, 2021

(CC BY 4.0) | ISSN 2525-3409 | DOI: http://dx.doi.org/10.33448/rsd-v10i9.18333

425.

Santos, G. D. R., Dias, I. C. D. R., Ventura, C. A., \& Fonseca, F. M. (2016). Variabilidade Genética De Isolados Brasileiros De Histoplasma capsulatum. Revista Uningá Review, 28(2).

Severo, C. B., Gazzoni, A. F., \& Severo, L. C. (2009). Capítulo 3: criptococose pulmonar. Jornal Brasileiro de Pneumologia, 35(11), $1136-1144$.

Silva, S. P., Costa, C. B. L., Silva, J. D. F., Alves, R. R. V., Silva, G. A. S., Freitas, A. F. S, \& Napoleão, T. H. (2021). Mecanismos de resistência de Cryptococcus spp. e compostos de plantas como ferramentas para combatê-los. Research, Society and Development, 10 (2), e57810212819-e57810212819.

Sloan, D. J., \& Parris, V. (2014). Cryptococcal meningitis: epidemiology and therapeutic options. Clinical epidemiology, 6, 169.

Srikanta, D., Santiago-Tirado, F. H., \& Doering, T. L. (2014). Cryptococcus neoformans: historical curiosity to modern pathogen. Yeast, 31(2), 47-60.

Souza, J. A. M. D. O. (2018). Variabilidade genética de Cryptococcus ambientais na cidade do Salvador-BA (Dissertação de Mestrado). Universidade Federal da Bahia, Salvador, Bahia, Brasil.

Tamura, K., Peterson, D., Peterson, N., Stecher, G., Nei, M., \& Kumar, S. (2011). MEGA5: molecular evolutionary genetics analysis using maximum likelihood, evolutionary distance, and maximum parsimony methods. Molecular biology and evolution, 28(10), 2731-2739.

Trilles, L., Lazéra, M. D. S., Wanke, B., Oliveira, R. V., Barbosa, G. G., Nishikawa, M. M., \& Meyer, W. (2008). Regional pattern of the molecular types of Cryptococcus neoformans and Cryptococcus gattii in Brazil. Memórias do Instituto Oswaldo Cruz, 103, 455-462. 